Mycologia, 97(5), 2005, pp. 1034-1046.

(C) 2005 by The Mycological Society of America, Lawrence, KS 66044-8897

\title{
Phylogenetics and evolution of nematode-trapping fungi (Orbiliales) estimated from nuclear and protein coding genes
}

Yan $\mathrm{Li}$

Laboratory for Conservation and Utilization of Bioresources, Yunnan University, Kunming 650091, Yunnan Province, PR China

Kevin D. Hyde

Rajesh Jeewon

Lei Cai

Dhanasekaran Vijaykrishna

Centre for Research in Fungal Diversity, Department of Ecology E Biodiversity, The University of Hong Kong, Pokfulam Road, Hong Kong SAR, PR China

Keqin Zhang ${ }^{1}$

Laboratory for Conservation and Utilization of Bioresources, Yunnan University, Kunming 650091, Yunnan Province, PR China

Abstract: The systematic classification of nematodetrapping fungi is redefined based on phylogenies inferred from sequence analyses of 28S rDNA, 5.8S rDNA and $\beta$-tubulin genes. Molecular data were analyzed with maximum parsimony, maximum likelihood and Bayesian analysis. An emended generic concept of nematode-trapping fungi is provided. Arthrobotrys is characterized by adhesive networks, Dactylellina by adhesive knobs, and Drechslerella by constricting-rings. Phylogenetic placement of taxa characterized by stalked adhesive knobs and nonconstricting rings also is confirmed in Dactylellina. Species that produce unstalked adhesive knobs that grow out to form loops are transferred from Gamsylella to Dactylellina, and those that produce unstalked adhesive knobs that grow out to form networks are transferred from Gamsylella to Arthrobotrys. Gamsylella as currently circumscribed cannot be treated as a valid genus. A hypothesis for the evolution of trapping-devices is presented based on multiple gene data and morphological studies. Predatory and nonpredatory fungi appear to have been derived from nonpredatory members of Orbilia. The adhesive knob is considered to be the ancestral type of trapping device from which constricting rings and networks were derived via two pathways. In the first pathway adhesive knobs retained their adhesive material forming simple two-dimension networks, eventually forming complex three-dimension networks. In the second pathway adhesive knobs lost

Accepted for publication 17 July 2005.

${ }^{1}$ Corresponding author. E-mail: kqzhang111@yahoo.com.cn their adhesive materials, with their ends meeting to form nonconstricting rings and they in turn formed constricting rings with three inflated-cells.

Key words: $\beta$-tubulin, evolution, fungi, phylogeny, predatory, systematics, rDNA

\section{INTRODUCTION}

Nematode-trapping fungi can produce various trapping devices to capture nematodes and other microscopic animals (Duddington 1951a, b; Barron 1977; Scholler et al 1999; Ahrén et al 2004) and are important in biological control (Dong et al 2004). The three basic types of trapping devices are adhesive knobs, constricting rings and adhesive networks and these can be subdivided further into seven types of trapping device (i.e., simple adhesive branches, unstalked adhesive knobs, stalked adhesive knobs, nonconstricting rings, constricting rings, two-dimensional networks and three-dimensional networks (Rubner 1996)). The majority of nematode-trapping fungi are hyphomycetes, placed within the Orbiliales (Orbiliomycetes) based on morphological and/or molecular studies. Other examples include Nematoctonus concurrens Drechsler whose teleomorph belongs to the genus Hohenbuehelia (Basidiomycetes), which uses both adhesive traps and adhesive spores, while Coprinus comatus (O.F. Müll) Gray and Pleurotus ostreatus (Jacq.) Kumm. (Basidiomycetes) produce toxins from specialized hyphal stalks to immobilize and digest the nematode (Barron and Thorn 1987, Dong et al 2004).

Since the pioneering work by Drechsler (1937), nematode-trapping fungi have been classified in a number of genera based on morphology of conidia (shape, septa and size) and conidiophores (branching, modifications of the apex). Traditional taxonomic concepts relied heavily on conidia and conidiophore morphology without taking in account the importance of trapping devices. This has led to a situation where species with diverse types of trapping devices have been assigned to one genus, while others with similar trapping devices can be found in different genera (Glockling and Dick 1994; Liu and Zhang 1994, 2003; Zhang et al 1996).

With molecular technology, traditional generic classification, generally based on the morphology of conidial characters, was challenged. Rubner (1996) first used trapping structure to try to rationalize the 
classification of the nematode-trapping fungi, which was justified by the following molecular data. Phylogenies based on rDNA sequences have indicated that trapping devices are more informative than other morphological characters in delimiting genera (Liou and Tzean 1997, Pfister 1997, Ahrén et al 1998, Scholler et al 1999, Kano et al 2004). Ahrén et al (1998) found that nematode-tapping fungi clustered into three lineages: species with constricting rings, species with various adhesive structures (net, hyphae, knobs and nonconstricting rings) and species have no trapping devices. Based on results obtained from morphological and molecular characters, Hagedorn and Scholler (1999) and Scholler et al (1999) classified nematode-trapping fungi into four genera: Dactylellina characterized by stalked adhesive knobs including species characterized by nonconstricting rings and stalked adhesive knobs; Gamsylella characterized by adhesive branches and unstalked knobs; Arthrobotrys characterized by adhesive networks; and Drechslerella characterized by constricting rings.

In this study DNA sequences from $28 \mathrm{~S}$ and $5.8 \mathrm{~S}$ rDNA and $\beta$-tubulin were analyzed to understand the evolution of trapping devices and further examine the relationships among nematode-trapping fungi. Sequenced taxa were selected to provide evidence for: (i) the evolution of trapping devices and (ii) the importance of adhesive branches, unstalked knobs, stalked adhesive knobs and nonconstricting rings in the taxonomic placement of species.

\section{MATERIALS AND METHODS}

Morphological examination.-Isolates were cultured on cornmeal agar (CMA) at $25 \mathrm{C}$ for 1 wk to check the characters of conidia and conidiophores. To verify the morphology of trapping devices cultures were cut into small cubes and inoculated with the free-living nematode, Paragrellus redivius (Linne) Goodey at 25 C for 3$5 \mathrm{~d}$ (Duddington 1955, Wyborn et al 1969). All morphological characters were recorded and photographed. The mean measurement is based on 50 counts.

DNA extraction.-Fungal cultures were grown 1 wk on PDA at $25 \mathrm{C}$ before DNA extraction. The mycelia were scraped from the surface of the agar and used as starting material. DNA was extracted with a modified CTAB method as outlined by Jeewon et al (2002, 2004).

Amplification and sequence of genomic DNA.-DNA amplification was performed by polymerase chain reaction (PCR). Primer pairs LROR (Bunyard et al 1994) and LR5 (Vilgalys and Hester 1990), ITS5 and ITS4 (White et al 1990), Bt1ABt1B and Bt2ABt2B (Glass and Donaldson 1995) were used to amplify partial large subunit (28S), the complete ITS (including 5.8S) and partial $\beta$-tubulin, respectively.
The PCR reaction mixture consisted of $0.3 \mu \mathrm{L}$ of 1.5 units of Taq DNA polymerase, $5 \mu \mathrm{L}$ of $10 \times$ buffer, $1.5 \mu \mathrm{L}$ of $25 \mu \mathrm{m} \mathrm{MgCl} 2,4 \mu \mathrm{L}$ of $2.5 \mathrm{mM}$ dNTPs, $1.5 \mu \mathrm{L}$ of $10 \mu \mathrm{m}$ primer, $3 \mu \mathrm{L}$ of DNA template and made up to a final volume of $50 \mu \mathrm{L}$ with double-distilled sterile water. PCR reaction were performed with these steps: $3 \mathrm{~min}$ at $95 \mathrm{C}, 30$ cycles of $1 \mathrm{~min}$ at $94 \mathrm{C}, 50 \mathrm{~s}$ at $52 \mathrm{C}, 1 \mathrm{~min}$ at $72 \mathrm{C}$ and a final extension step of $10 \mathrm{~min}$ at $72 \mathrm{C}$. Amplified products were electrophoresed on $1 \%$ agarose gels to check for size and purity.

Purified PCR products were sequenced directly on both strands with the same primers that were used for amplification. Reactions were performed in an Applied Biosystem 3730 DNA Analyzer at the Genome Research Centre (University of Hong Kong). All the sequences have been deposited in GenBank (TABLE I).

Phylogenetic analysis.-DNA sequences were aligned with additional sequences obtained from GenBank (TABLE I) with BioEdit (Hall 1999) and Clustal X 1.83 (Thompson et al 1997). Manual gap adjustments were made to improve the alignment. Phylogenetic analyses were conducted with PAUP* version 4.0b10 (Swofford 2002) and MrBayes 3.0b4 (Huelsenbeck and Ronquist 2001). Alignment gaps were treated as missing data. The characters were weighted at different transition-transversion ratios (TTr) to determine the most appropriate parameters giving the best trees. Maximum parsimony trees were found with 1000 heuristic search and including parsimony-informative characters in stepwise (random) addition and tree bisection and reconstruction (TBR) as branch swapping algorithm. MAXTREES were set to 5000, branches of zero length were collapsed and all most parsimonious trees were saved. Branch support for all parsimony analyses was estimated by performing 1000 bootstrap replicates (Felsenstein 1985) with a heuristic search consisting of 10 random-addition replicates for each bootstrap replicate. Partition homogeneity test (Farris et al 1995, Huelsenbeck et al 1996), as implemented in PAUP, was performed to check whether different genes could be combined.

To select the best-fit model of evolution for the maximum likelihood (ML) and Bayesian analyses, MrModeltest 2 (Posada and Crandall 1998, Nylander 2004) was used based on a tree calculated under neighbor joining criterion under the Jukes Cantor model (JC69) (Jukes and Cantor 1969). ML tree was built with a heuristic search, addition sequence set to "as", with TBR branch swapping algorithm. Bayesian analyses were conducted with MrBayes 3.0b4. Markov chains were run for 1000000 generations and trees were sampled every 100th generation resulting in 10000 trees. The burnin number was determined by graphically visualizing the likelihood scores. The first 1000 trees, which represented the burn-in phase of the analysis, were discarded, and the remaining 9000 trees were used for calculating posterior probabilities in the consensus tree.

Descriptive tree statistics tree length (TL), consistency index (CI), retention index (RI), rescaled consistency index (RC), homoplasy index (HI) and log likelihood (-Ln L) were calculated for all trees generated under parsimony and likelihood optimality criteria. Kishino-Hasegawa tests (Kishino and Hasegawa 1989) and Templeton tests (Tem- 
TABLE I. List of taxa and GenBank accession numbers used in this study

\begin{tabular}{|c|c|c|c|c|c|c|c|}
\hline \multirow[b]{3}{*}{ Species } & \multirow{3}{*}{$\begin{array}{c}\text { Source of } \\
\text { cultures }\end{array}$} & \multirow{3}{*}{$\begin{array}{c}\text { Geographic } \\
\text { origin }\end{array}$} & \multirow{3}{*}{$\begin{array}{c}\text { Trapping } \\
\text { devices }\end{array}$} & \multicolumn{4}{|c|}{ GenBank Accession Numbers } \\
\hline & & & & \multicolumn{2}{|c|}{ rDNA } & \multicolumn{2}{|c|}{$\beta$-tubulin } \\
\hline & & & & ITS & $28 \mathrm{~S}$ & $\beta-1 \mathrm{~A} 1 \mathrm{~B}$ & $\beta-2 A 2 B$ \\
\hline A. anchonia & CBS109.37 & USA & CR & AY965753 & AY902799 & AY965786 & AY965815 \\
\hline A. brochopaga & CBS218.61 & USA & CR & U72609 & AY261176 & AY965794 & AY965823 \\
\hline A. entomopaga & CBS642.80 & Australia & $\mathrm{AK}$ & AY965758 & AY965774 & AY965802 & AY965831 \\
\hline M. candidum & YMF1.00036 & China & AK\&NCR & AY965749 & AY902801 & AY965778 & AY965808 \\
\hline M. cionopagum & CBS585.91 & Portugal & $\mathrm{AK} \& \mathrm{NW}$ & AY965756 & AY965772 & AY965800 & AY965829 \\
\hline M. drechsleri & YMF1.00573 & China & $\mathrm{AK}$ & AY695063 & AY965765 & AY965784 & AY965813 \\
\hline M. ellipsosporum & CA-7 & China & $\mathrm{AK}$ & AY965759 & AY261157 & AY965803 & AY965832 \\
\hline M. gephyrophagum & CBS178.37 & USA & $\mathrm{AK} \& \mathrm{NW}$ & U51974 & AY261173 & AY965792 & AY965821 \\
\hline M. haptotylum & SQ-95-2 & China & $\mathrm{AK}$ & AF106523 & AY902791 & AY965775 & AY965805 \\
\hline M. lysipagum & YMF1.00535 & China & AK\&NCR & AY695067 & AY261165 & AY965782 & AY965812 \\
\hline M. mammillatum & CBS229.54 & UK & $\mathrm{AK}$ & AY902794 & AY902802 & AY965795 & AY965824 \\
\hline M. multiseptatum & YMF1.00127 & China & $\mathrm{AK}$ & AY965751 & AY965764 & AY965781 & AY965811 \\
\hline M. parvicolle & YMF1.00029 & China & $\mathrm{AK} \& \mathrm{AB}$ & AY965748 & AY965761 & AY965777 & AY965807 \\
\hline M. phymatopagum & CBS325.72 & Netherlands & $\mathrm{AK} \& \mathrm{AB}$ & U51970 & AY261156 & AY965798 & AY965827 \\
\hline M. robustum & YMF1.01413 & China & $\mathrm{AK} \& \mathrm{AB}$ & AY965755 & AY965769 & AY965789 & AY965818 \\
\hline M. sclerohyphum & YMF1.00041 & China & $\mathrm{AK}$ & AY902806 & AY965762 & AY965779 & AY965834 \\
\hline M. shuzhengense & YMF1.00584 & China & $\mathrm{AK} \& \mathrm{AB}$ & AY965752 & AY965766 & AY965785 & AY965814 \\
\hline M. sichuanense & YMF1.00023 & China & AK\&UCR & AY902795 & AY902803 & AY965776 & AY965806 \\
\hline M. tentaculatum & CBS206.64 & USA & $\mathrm{AK}$ & AF106531 & AY902792 & AY965793 & AY965822 \\
\hline M. thaumasium & CBS176.37 & USA & NW & U51972 & AY261137 & AY965791 & AY965819 \\
\hline M. yunnanense & CBS615.95 & China & AK\&UCR & AY965757 & AY965773 & AY965801 & AY965830 \\
\hline$M . \mathrm{sp}$ & KG-55 & China & AK\&UCR & AY965747 & AY965760 & AY965804 & AY965833 \\
\hline M. sp & YMF1.01405 & China & AK\&UCR & AY965754 & AY965768 & AY965788 & AY965817 \\
\hline D. arcuata & CBS174.89 & UK & $\mathrm{AK} \& \mathrm{NW}$ & AF106527 & AY261129 & AY965790 & AY965820 \\
\hline D. asthenopaga & CBS262.83 & Australia & $\mathrm{AK}$ & U51962 & AY965770 & AY965796 & AY965825 \\
\hline D. copepodii & CBS487.90 & New Zealand & $\mathrm{AK}$ & U51964 & AY965771 & AY965799 & AY965828 \\
\hline D. leptospora & YMF1.00117 & China & AK\&UCR & AY965750 & AY965763 & AY965783 & AY965809 \\
\hline D. oxyspora & YMF1.10000 & China & None & AF106537 & AY965767 & AY965787 & AY965816 \\
\hline D. rhombospora & CBS280.70 & Germany & None & AY902793 & AY902790 & AY965797 & AY965826 \\
\hline D. varietas & YMF1.00118 & China & AK\&UCR & AY902805 & AY902800 & AY965780 & AY965810 \\
\hline Neurospora crassa & CBS709.71 & USA & & AY681193 & AY681158 & AY974799 & AY681226 \\
\hline Sordaria fimicola & CBS723.96 & $\begin{array}{c}\text { Papua New } \\
\text { Guinea }\end{array}$ & & AY681188 & AY681160 & AY974800 & AY681228 \\
\hline
\end{tabular}

$\mathrm{AK}=$ adhesive knobs, $\mathrm{AB}=$ adhesive branches, $\mathrm{CR}=$ constricting rings, $\mathrm{UCR}=$ non-constricting rings, $\mathrm{NW}=$ networks.

pleton 1983) were performed for all trees to compare tree topologies. Trees were figured in Treeview (Page 1996).

\section{RESULTS}

rDNA data.-The 28S and 5.8S dataset included 32 taxa, each with 1046 characters. Eleven ambiguously aligned characters were excluded. The remaining 1035 characters included 808 constant characters, 28 variable parsimony-uninformative characters and 199 parsimony-informative characters. Unweighted analysis resulted in 15 parsimony trees. Three parsimony trees were obtained when transition was weighted 1.5 times over transversion. SYM+I+G were selected as the best-fit model for maximum likelihood and Bayesian analyses.
The Bayesian tree with bootstrap supported from 1000 replicated and Bayesian posterior probability (bpp) are provided (FIG. 1).

Taxa forming both nonconstricting rings and stalked adhesive knobs clustered with taxa forming only adhesive knobs within clade A ( $85 \%$ bpp). Two nonpredatory fungi, Dactylella rhombospora Grove and D. oxyspora (Sacc. \& Marchal) Matsush., and two predatory fungi, Monacrosporium multiseptatum H.Y. Su \& K.Q. Zhang and D. varietas Y. Li, K.D. Hyde \& K.Q. Zhang, grouped together as defined in clade D with 99\% bpp and $99 \%$ bootstrap support. Species with constricting rings (clade $B$ ) received high support as a monophyletic clade (99\% bpp and 99\% bootstrap support). Taxa characterized by unstalked adhesive knobs and adhesive branches did not cluster 


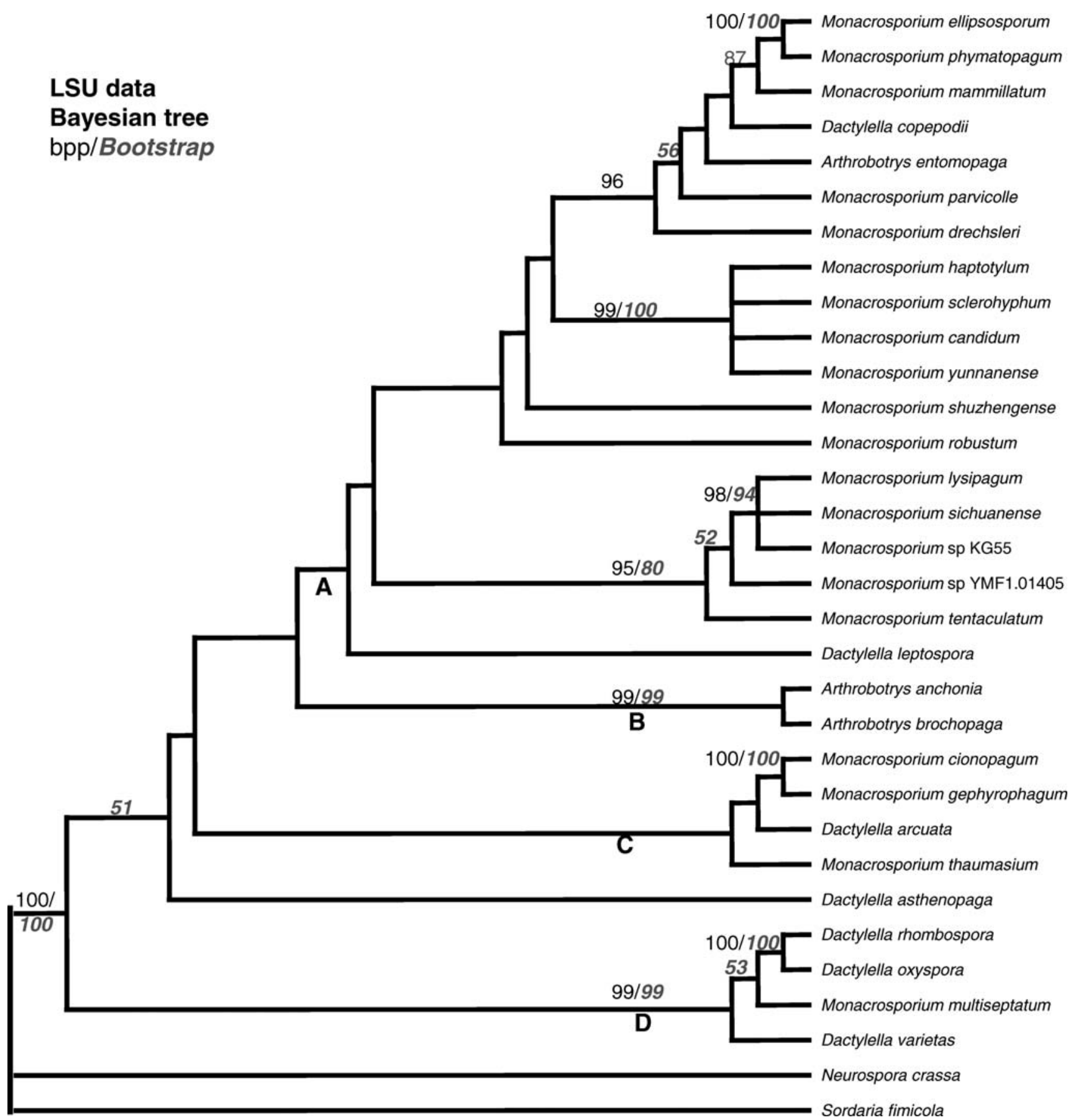

FIG. 1. Bayesian tree based on rDNA sequences. The number at each branch point represents percentage bootstrap support calculated from 1000 replicates and Bayesian posterior probability. Neurospora crassa and Sordaria fimicola are used as outgroups.

together. Monacrosporium parvicolle (Drechsler) R.C. Cooke \& C.H. Dickinson, M. phymatopagum (Drechsler) Subram., M. robustum J.S. McCulloch and $M$. shuzhengense X.F. Liu \& K.Q. Zhang characterized by unstalked adhesive knobs with adhesive hyphae growing out to form loops clustered in clade A, while
M. cionopagum (Drechsler) Subram., M. gephyrophagum (Drechsler) Subram. and D. arcuata Scheuer \& J. Webster, characterized by unstalked adhesive knobs with adhesive hyphae that grow out to form networks, grouped with $M$. thaumasium (Drechsler) de Hoog \& Oorschot (clade C). 


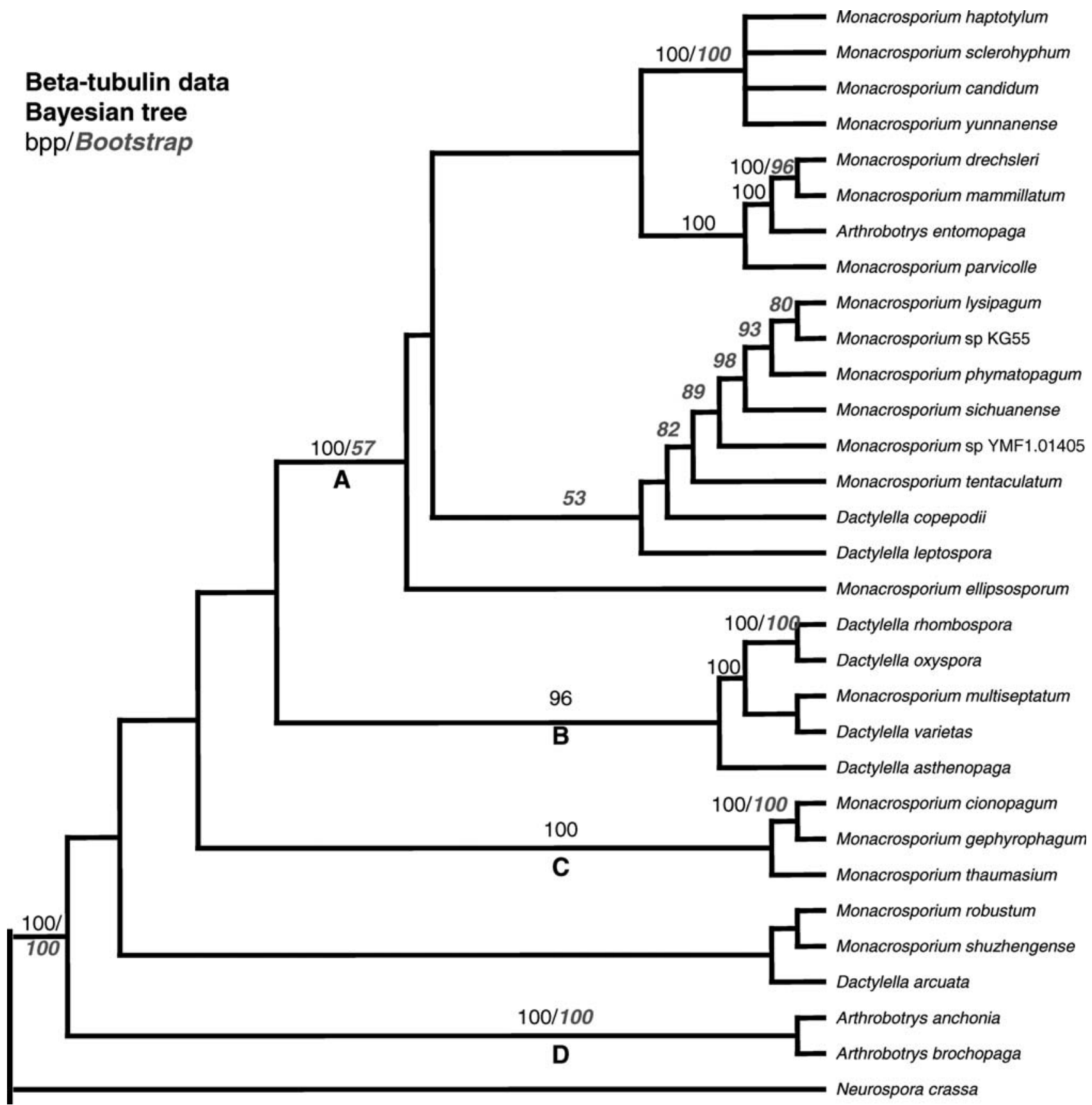

FIG. 2. Bayesian tree generated from $\beta$-tubulin sequences. Bootstrap values less than $50 \%$ and Bayesian posterior probability less than $95 \%$ are not shown. Neurospora crassa and Sordaria fimicola are used as outgroups.

$\beta$-tubulin.-The final alignment of $\beta$-tubulin- 1 amplified with Bt1A and Bt1B and $\beta$-tubulin-2 amplified with Bt2A and Bt2B included 32 taxa each with 1203 characters; 546 ambiguously aligned characters were excluded. The resulting dataset consisted of 219 parsimony informative characters. Unweighted heuristic searches resulted in 12 trees, while one tree was obtained when a transition-transversion ratio of $1.5: 1$ was used. There were no significant differences between trees generated from weighted and unweighted parsimony. The best-fit model selected for likelihood and Bayesian analyses by MrModeltest was GTR+G.

There were no contradictions in topologies among the Bayesian, parsimony and likelihood trees. The Bayesian tree is provided (FIG. 2). The tree based on $\beta$-tubulin data is similar to the trees based on rDNA data in topology, but higher support was received for clade A (FIG. 2). Species forming both stalked 
adhesive knobs and nonconstricting rings group with species forming only stalked adhesive knobs in clade A with $100 \%$ bpp and 57\% bootstrap support. Nonpredatory fungi, Dactylella rhombospora and $D$. oxyspora, appeared to be related phylogenetically to Monacrosporium multiseptatum and D. varietas, taxa with stalked adhesive knobs, within clade B (96\% bpp). Species with constricting rings (clade D) and species with adhesive networks (clade C) were supported as monophyletic clades with $100 \%$ bpp, while species that produce both unstalked adhesive knobs and adhesive branches did not group together as a monophyletic clade. Phylogenies obtained from $\beta$-tubulin sequences are generally concordant with those based on rDNA sequences. The only topological difference is the phylogenetic placement of $M$. robustum and $M$. shuzhengense, which group within clade A in rDNA data as compared to outside clade A in $\beta$-tubulin phylogenies. Affinities of $M$. phymatopagum and $M$. parvicolle are well supported in clade A. However the phylogenetic affinities of $M$. robustum and $M$. shuzhengense cannot be established due to the difference observed in their phylogenetic placement. They were sister taxa to Dactylella arcuata (unstalked adhesive knobs and networks) in $\beta$-tubulin analyses (FIG. 2), however in rDNA analyses they were basal to clade A (FIG. 1).

Combined dataset. - A partition homogeneity test of the full dataset, combining rDNA (28S and 5.8S rDNA) and $\beta$-tubulin (1A1B and 2A2B), indicated that the different datasets could be combined $(P$ $>0.05)$. The combined dataset consisted of 32 taxa each with 2249 characters. A total of 548 ambiguously aligned characters were excluded. Of the remaining 1701 characters, 1115 were constant and 431 were parsimony-informative.

Equally weighted maximum parsimony analysis generated two trees and weighted parsimony with a transition transversion ratio of $1.5: 1$ resulted in three trees, which were not significantly different from each other. For ML analysis, the best-fit model determined by MrModeltest 2 was the $\mathrm{GTR}+\mathrm{I}+\mathrm{G}$ model.

While minor topological differences were obtained under different optimality criteria (maximum parsimony, maximum likelihood and Bayesian), the topology among and within the well-supported clades (clades A, B and C) remained the same. Some of the major clades that collapsed and were not supported statistically in the rDNA and $\beta$-tubulin datasets were resolved and received reasonable bpp and bootstrap support in the combined dataset (FIG. 3).

Clade A received $100 \%$ bpp and $90 \%$ bootstrap support based on combined datasets. Taxa with both nonconstricting rings and stalked adhesive knobs are not phylogenetically unrelated from taxa with only stalked adhesive knobs (subclades A2 and A3, FIG. 3). Clade B comprised two nonpredatory taxa (no trapping devices) and three predatory taxa with high support (100\% bpp and $91 \%$ bootstrap support). This is consistent with results obtained from sequences analyses of individual genes (FIGS. 1, 2). Species with constricting rings (clade C) and Monacrosporium thaumasium with networks received $100 \%$ bpp. Phylogenetically M. gephyrophagum, M. cionopagum and Dactylella arcuata appear to be closely related to M. thaumasium. Another major topological difference observed in the combined dataset is the phylogenetic placement of taxa with unstalked adhesive knobs and adhesive branches. Monacrosporium robustum and $M$. shuzhengense formed a monophyletic clade (98\% bpp and $60 \%$ bootstrap support) and sister to clade A (FIG. 3) as compared to sister to Dactylella arcuata (FIG. 2). Phylogenetic results obtained from the combined dataset are used to infer relationship among nematode-trapping fungi because most clades received good support.

\section{DISCUSSION}

Phylogeny of nematode-trapping fungi.-Nematodetrapping fungi previously were classified based on morphological characters of the conidia and comprised three genera, Arthrobotrys, Dactylella and Monoacrosporium subramanian (1963). Recent studies with ITS and 18S rDNA sequences indicated that trapping devices are more informative than other morphological structures in delimiting genera (Liou and Tzean 1997, Pfister 1997, Ahrén et al 1998, Scholler et al 1999), and based on these studies a new classification scheme with four genera (Arthrobotrys, Dactylellina, Gamsylella and Drechslerella) was proposed by Scholler et al (1999).

Dactylellina._Dactylellina M. Morelet was recognized by Scholler et al (1999) for species characterized by stalked adhesive knobs and included those species producing nonconstricting rings. Species producing both nonconstricting rings and stalked adhesive knobs could not be separated from the group producing only stalked adhesive knobs based on sequence analysis of the $18 \mathrm{~S}$ and ITS regions of rDNA. Scholler et al (1999) however only included one taxon, Monacrosporium haptotylum (Drechsler) X.Z. Liu \& K.Q. Zhang, which produced both nonconstricting rings and stalked adhesive knobs in their analyses. Furthermore nonconstricting rings were not produced by 


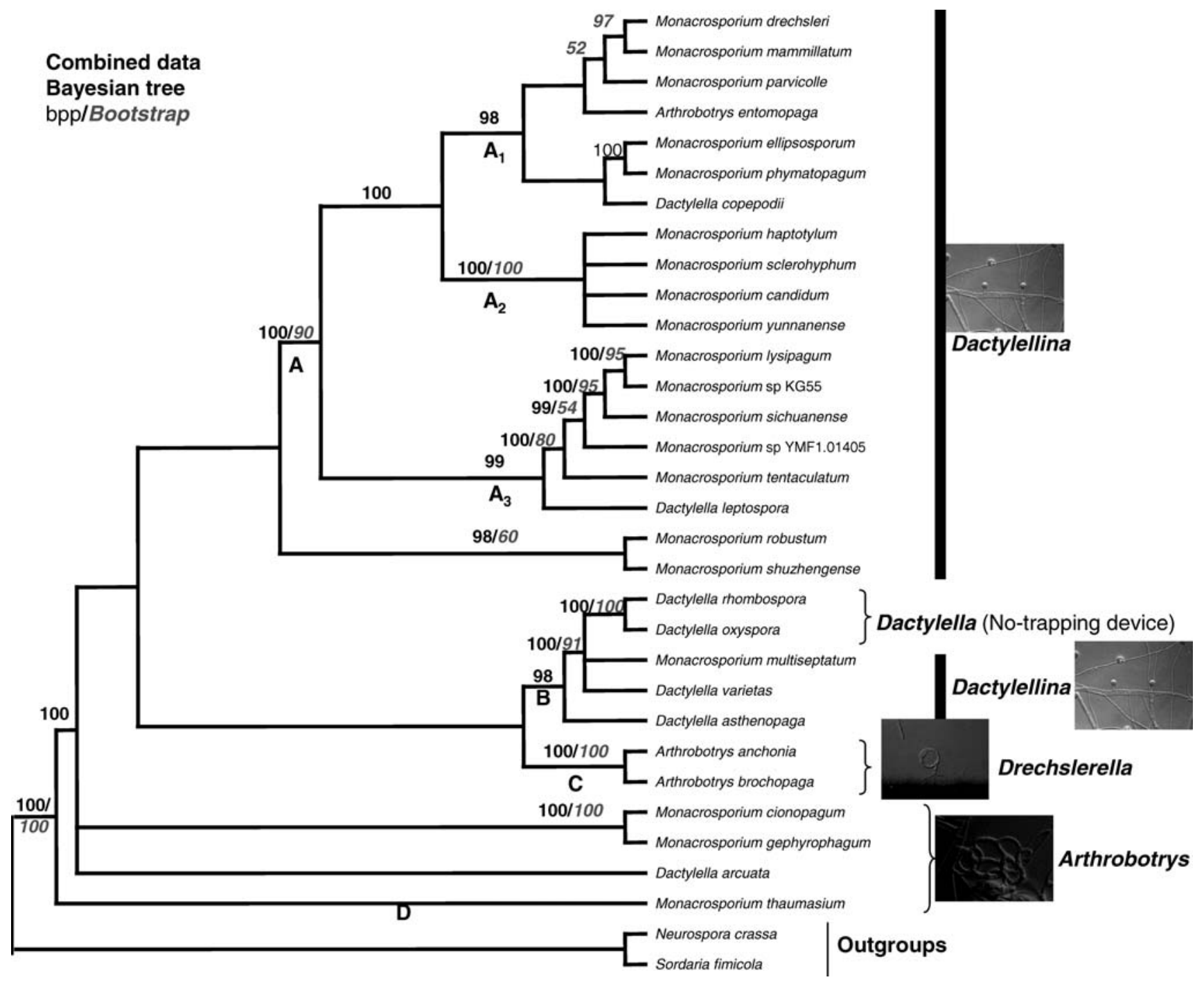

FIG. 3. Phylogenetic tree based on combined dataset of rDNA and $\beta$-tubulin. Neurospora crassa and Sordaria fimicola are used as outgroups. Bootstrap values obtained from 1000 replications and Bayesian posterior probability are shown above respective nodes.

this strain in culture. The inclusion of taxa producing nonconstricting rings in Dactylellina remained questionable given the limited taxon sampling.

In our study we included eight taxa producing both nonconstricting rings and stalked adhesive knobs. Phylogenies derived from combined gene datasets (rDNA and $\beta$-tubulin) do not support the monophyly of species with both nonconstricting rings and stalked adhesive knobs (FIG. 3, clade A) which group with species producing stalked adhesive knobs only. Within clade A, subclades A2 and A3 comprise taxa forming both nonconstricting rings and stalked adhesive knobs and taxa forming only stalked adhesive knobs with $100 \%$ bpp and $99 \%$ bootstrap support. Our data therefore support the conclusions of Scholler et al (1999) in defining Dactylellina as including species that produce stalked adhesive knobs, with some species also producing nonconstricting rings.

The nonpredatory species Dactylella oxyspora and D. rhopalota Drechsler have been shown to be closely related to species producing constricting rings and species producing adhesive knobs (Ahrén et al 1998, Liou and Tzean 1997), with low statistical support. In our study however we used the nonpredatory taxa $D$. rhombospora and $D$. oxyspora and found them to have close affinities to species with adhesive knobs. It is possible that taxa with adhesive knobs have evolved from nonpredatory species, having gained the capability of capturing nematodes with these knobs, as concluded by Ahrén et al (1998). On the other hand 
these taxa might have produced adhesive knobs at one time, but this trapping device might have been lost in some species in their subsequent development, thus losing their ability to trap nematodes. We have observed repeatedly that several strains characterized by adhesive knobs fail to produce any kind of trapping devices after successive subculturing.

Gamsylella.-The new genus Gamsylella was proposed for species characterized by producing unstalked adhesive knobs and adhesive branches Scholler et al (1999). Six species were placed in this genus including Dactylella arcuata, D. lobata Dudd., Monacrosporium gephyrophagum, M. robustum, M. parvicolle and M. phymatopagum. In this study we included these six taxa plus a new species $M$. shuzhengense. Morphological observations from culture revealed that none of these taxa only formed unstalked adhesive knobs, which was just one temporary structure formed at the first stage of life. These unstalked knobs could then grow out to form branches, which will further change in different species. In D. arcuata, M. gephyrophagum and $M$. cionopagum, the branches then fuse to form two- or three-dimension adhesive networks, whereas in M. parvicolle, M. shuzhengese, D. lobata and $M$. phymatopagum the branches fuse to form loops or helices. Therefore, based on our observation, unstalked adhesive knobs should not be treated as a unique type of trapping-device and this character should not be given taxonomic importance.

Scholler et al (1999) showed Gamsylella to be monophyletic when using Dactylella arcuata, D. lobata, M. gephyrophagum and M. phymatopagum in their analyses.

In this study we used more representatives of Gamsylella sensu Scholler et al (i.e. Dactylella arcuata, Monacrosporium cionopagum, M. gephyrophagum, M. parvicolle, $M$. phymatopagum, $M$. robustum and $M$. shuzhengense) and a combination of rDNA and $\beta$ tubulin to provide a better phylogenetic interpretation. Monacrosporium parvicolle and M. phymatopagum grouped with Dactylellina species (FIG. 3, clade A). Monacrosporium shuzhengese and $M$. robustum were sister taxa to Dactylellina. Dactylella arcuata, Monacrosporium gephyrophagum and M. cionopagum, which form unstalked adhesive knobs that grow into networks, are close to M. thaumasium, which Scholler et al (1999) included in Arthrobotyrs. Kano et al (2004) found that 14 species with networks grouped as a monophyletic clade supported by ITS data and $M$. gephyrophagum and $M$. cionopagum also were related closely to this clade.

Based on findings reported here, we think it is necessary to emend the genetic concepts of nema- tode-trapping fungi. Dactylella arcuata, Monacrosporium gephyrophagum and $M$. cionopagum are transferred from Gamsylella to Arthrobotrys, a genus where all species form unstalked adhesive knobs that develop into adhesive networks. The other taxa in Gamsylella (i.e., M. parvicolle, M. phymatopagum, M. shuzhengense and $M$. robustum) are transferred to an emended Dactylellina, a genus in which species can form stalked adhesive knobs, with some species producing nonconstricting rings or unstalked adhesive knobs that develop into loops; Gamsylella does not merit generic status.

Dactylellina candidum.-Rubner (1996) treated Monacrosporium candidum (Nees) X.Z. Liu \& K.Q. Zhang, M. haptotylum (Drechsler) X.Z. Liu \& K.Q. Zhang and M. sclerohyphum (Drechsler) X.Z. Liu \& K.Q. Zhang as conspecific under the name $M$. haptotylum. Monacrosporium yunnanense K.Q. Zhang, X.Z. Liu \& L. Cao (CBS 615.95) is similar to $M$. candidum in having spindle-shaped, mostly 4septate conidia, and branched conidiophores, bearing 3-10 conidia in a loose capitate arrangement. The only difference being that $M$. candidum and $M$. yunnanense form both stalked adhesive knobs and nonconstricting rings, while $M$. haptotylum and $M$. sclerohyphum form only stalked adhesive knobs. These four taxa (FIG. 3, subclade A2) are phylogenetically closely related receiving high bootstrap support and bbp (FIGS. 1-3), based on the rDNA, $\beta$-tubulin and combined datasets, and this grouping agrees well with the morphological characters of the taxa. These four taxa therefore can be considered as conspecific and should be named Dactylellina candidum based on our results.

Arthrobotrys gephyropaga.-In this study Monacrosporium cionopagum is closely related to $M$. gephyrophagum with $100 \%$ bpp and $100 \%$ bootstrap support (FIGS. 1, 2, 3) based on molecular data. This is in agreement with the morphological based classification scheme of Rubner (1996) in which $M$. cionopagum is considered a synonym of $M$. gephyrophagum. Monacrosporium gephyrophagum is transferred to Arthrobotrys based on the molecular results of this study.

Accepted genera of nematode trapping fungi.-Based on multigene data analyses, three genera, Arthrobotrys, Dactylellina and Drechslerella, are retained in the redefinition of the circumscription of three genera of nematode-trapping Orbiliaceous fungi. Species forming constricting rings (always with three cells) are placed in Drechslerella. Arthrobotrys is characterized by species forming adhesive net- 
works. Taxa with unstalked adhesive knobs that grow out to form simple adhesive networks also are assigned to Arthrobotrys. Species that capture nematodes mainly by stalked adhesive knobs are placed in Dactylellina. Taxa with both nonconstricting rings and stalked adhesive knobs and taxa with unstalked adhesive knobs that grow out to form loops also are assigned to Dactylellina.

\section{KEYS TO GENERA OF NEMATODE-TRAPPING FUNGI}

1 Trapping-device a constricting ring, which consists of three inflated cells with a short, strong stalk ................ Drechslerella

$1^{\prime}$ Trapping-device not a constricting ring, but various adhesive trapping devices . . . . . . . 2

2 Trapping device unstalked adhesive knobs that develops into an adhesive network or adhesive networks only. ............ Arthrobotrys

2' Trapping device stalked adhesive knobs, some with non-constricting rings, or unstalked adhesive knobs which grow out to form adhesive branches and loops ............. Dactylellina

Taxonomic changes

Arthrobotrys arcuata (Scheuer \& J. Webster) Y. Li, comb. nov.

Basionym: Dactylella arcuata Scheuer \& J. Webster, Mycol Res 94:718. 1990

? Monacrosporium arcuatum (Scheuer \& J. Webster) A. Rubner, Stud Mycol 39:49. 1996

? Gamsylella arcuata (Scheuer \& J. Webster) M. Scholler, Sydowia 51:108.1999.

Arthrobotrys gephyropaga (Drechsler) Y. Li, comb. nov.

Basionym: Dactylella gephyropaga Drechsler, Mycologia 29:512. 1937

= Monacrosporium gephyrophagum (Drechsler) Subram., J Indian Bot Soc 42:293. 1963

$\equiv$ Golovinia gephyropaga (Drechsler) Mekht., Mikol Fitopatol 1:276. 1967

$\equiv$ Gamsylella gephyropaga (Drechsler) M. Scholler, Sydowia 51:108.1999.

= Dactylella cionopaga Drechsler, Mycologia 42:30. 1950

= Monacrosporium cionopagum (Drechsler) Subram., J Indian Bot Soc 42:293. 1963

= Golovinia cionopaga (Drechsler) Mekht., Khishchnye nematofagovye Griby-Gifomitsety: 166. 1979.

Dactylellina candidum (Nees: Fr.) Y. Li, comb. nov.

Basionym: Dactylium candidum Nees, Syst Pilze Schw 58. 1817: Fries Syst Mycol 3:44. 1829 $\equiv$ Dactylaria candida (Nees : Fr.) Sacc., Sylloge Fungorum 4: 195. 1886

$\equiv$ Candelabrella candida (Nees: Fr.) Rifai., Reinwardtia 7:369. 1968

$\equiv$ Arthrobotrys candida (Nees: Fr.) S. Schenck, W.B. Kendr. \& Pramer, Can J Bot 55:982. 1977

$\equiv$ Dactylella candida (Nees: Fr.) de Hoog \& Oorschot, Stud Mycol 26:102. 1985

$\equiv$ Monacrosporium candidum (Nees: Fr.) Xing Z. Liu \& K.Q. Zhang, Mycol Res 98:864. 1994

= Golovinia capitulopaga Mekht., Khishchnye nematofagovye Griby-Gifomitsety: 169. 1979

= Dactylaria haptotyla Drechsler, Mycologia 42:48. 1950

$\equiv$ Golovinia haptotyla (Drechsler) Mekht, Mikol Fitopatol 1:277. 1967

$\equiv$ Candelabrella haptotyla (Drechsler) Rifai, Reinwardtia 7:369. 1968

$\equiv$ Arthrobotrys haptotyla (Drechsler) S. Schenck, W.B. Kendr. \& Pramer, Can J Bot 55:983. 1977

= Dactylella haptotyla (Drechsler) de Hoog \& Oorschot, Stud Mycol 26:111. 1985

= Monacrosporium haptotylum (Drechsler) Xing Z. Liu \& K.Q. Zhang, Mycol Res 98:865. 1994.

$\equiv$ Dactylellina haptotyla (Drechsler) M. Scholler, Sydowia 51:108. 1999.

= Dactylaria sclerohypha Drechsler, Mycologia 42:57. 1950.

$\equiv$ Monacrosporium sclerohyphum (Drechsler) Xing Z. Liu \& K.Q. Zhang, Mycol Res 98:865. 1994.

= Monacrosporium yunnanense K.Q. Zhang, Xing Z. Liu \& L. Cao, Mycol Res 100:275. 1996.

$\equiv$ Dactylellina yunnanensis (K.Q. Zhang, Xing Z. Liu \& L. Cao) M. Scholler, Sydowia 51:108. 1999.

Dactylellina lobata (Dudd.) Y. Li, comb. nov.

Basionym: Dactylella lobata Dudd, Trans Br Mycol Soc 34:94. 1951b

$\equiv$ Monacrosporium lobatum (Dudd.) A. Rubner, Stud Mycol 39:80. 1996

$\equiv$ Gamsylella lobata (Dudd.) M. Scholler, Sydowia 51:108.1999.

Dactylellina parvicolle (Drechsler) Y. Li, comb. nov. Basionym: Dactylella parvicollis Drechsler, Sydowia 15:13. 1962 (1961)

$\equiv$ Monacrosporium parvicolle (Drechsler) R.C. Cooke \& C.H. Dickinson [as "parvicollis"], Trans Br Mycol Soc 48:622. 1965

$\equiv$ Golovinia parvicollis (Drechsler) Mekht., Khishchnye nematofagovye Griby-Gifomitsety: 162. 1979

$\equiv$ Gamsylella parvicollis (Drechsler) M. Scholler, Sydowia 51:109.1999.

Dactylellina phymatopaga (Drechsler) Y. Li, comb. nov.

Basionym: Dactylella phymatopaga Drechsler, Mycologia 46:775. 1954 
= Monacrosporium phymatopagum (Drechsler) Subram., J Indian Bot Soc 42:293. 1963

$\equiv$ Golovinia phymatopaga (Drechsler) Mekht., Khishchnye nematofogovye Griby-Gifomitsety: 165. 1979

= Gamsylella phymatopaga (Drechsler) M. Scholler, Sydowia 51:109.1999.

Dactylellina robusta (J.S. McCulloch) Y. Li, comb. nov.

Basionym: Monacrosporium robustum J.S. McCulloch, Trans Br Mycol Soc 68:177. 1977

$\equiv$ Gamsylella robusta (J.S. McCulloch) M. Scholler, Sydowia 51:109.1999.

Evolution of trapping-devices. - The concept that predatory nematode-trapping fungi evolved from nonpredatory taxa was proposed by Rubner (1996) who provided a hypothetical model for the development of trapping devices. Pfister (1997) also showed that the trapping Orbiliaceae formed a clade within the nonpredatory members of the family. Scholler et al (1999) further concluded that, based on 18S and ITS data, predatory species originated from nonpredatory species within the genus Orbilia. Our findings support these previous studies.

Ahrén et al (1998) analyzed 18S rDNA and found that species with constricting rings are monophyletic and distinct from species with other adhesive trapping devices and nonpredatory species. They therefore suggested that the ability to capture nematodes have arisen at least twice, once in a lineage with species forming constricting rings and once in a lineage leading to the formation of adhesive trapping structures. Further molecular studies showed that taxa with adhesive networks were monophyletic and could be separated from other taxa with various adhesive-trapping devices (Scholler et al 1999, Kano et al 2004).

Liou and Tzean (1997) suggested that species with adhesive knobs should be treated as sister groups and taxa with constricting rings and those with adhesive networks were derived from these sister groups (Liou and Tzean 1997). The monophyly of species characterized by adhesive knobs is supported in our datasets (FIG. 3, clade A). Our data also show that the nonpredatory taxa, Dactylella rhombospora and D. oxyspora are closely related to three taxa with adhesive knobs (FIG. 3). This indicates that species with adhesive knobs have closer phylogenetic affinities to nonpredatory fungi than to species with adhesive networks and constricting rings (FIG. 3).

Adhesive knobs, adhesive networks and constricting rings are the three main nematode-trapping devices and they capture nematodes based on different mechanisms. Constricting rings comprise three cells that can inflate in a short time to strangle nematodes. Nematodes wriggle in networks and become trapped in the adhesive material lining the networks until they become exhausted and die. Adhesive knobs, however, trap nematodes at only one point and are not as efficient because nematodes can easily escape, while nematodes must wriggle into nonconstricting rings which can then break off and be carried away by the nematode. It suggested that possess constricting rings and adhesive networks should be more complex and better strategies for capturing nematodes and obtaining nutrition than adhesive knobs.

Species with more than one type of trapping device provide some evidence into how trapping-devices evolved in nematode trapping fungi from adhesive knobs to adhesive networks and constricting rings. One possible hypothesis for the evolution of various trapping devices based on phylogenetic analyses and large numbers of morphological observations is provided (FIG. 4).

As we know, nonconstricting rings usually are formed as a type of trapping device along with adhesive knobs in some species (e.g. Monacrosporium lysipagum). Our analyses also place species with nonconstricting rings and stalked adhesive knobs within clade A (FIG. 3). Species that form unstalked adhesive knobs then grow out to form loops (e.g. Monacrosporium parvicolle, $M$. phymatopagum and $M$. robustum), appear to be related to clade A (FIG. 3). These findings imply that ancestral adhesive knobs may grow out to form loops which then evolved into nonconstricting rings without adhesive materials (e.g. Monacrosporium lysipagum, D. leptospora and $M$. candidum). Both nonconstricting rings and constricting rings have three cells, stalks and no adhesive materials, even though nonconstricting rings cannot inflate and can be broken easily because of the long slender stalk. This similar structure suggested constricting rings might evolve from non constricting rings (FIG. 4, Branch $\mathrm{A}$ ).

Species with adhesive knobs and simple networks (Monacrosporium gephyrophagum and Dactylella arcuata) appear to be closely related to species with networks based on molecular datasets (FIGS. 1, 2). Unstalked adhesive knob could be observed to grow out to form branches and several branches that grew up from same hyphae could fuse simple twodimension network in $M$. gephyrophagum (CBS 178.37). Similar process could be observed in $D$. arcuata (CBS 174.89) but the branches grew up from different hyphae and finally fused three-dimension network. These results imply that ancestral adhesive knobs might grow out to form two-dimension networks and later evolve into species with threedimension networks (e.g. M. thaumasium) (FIG. 4, 


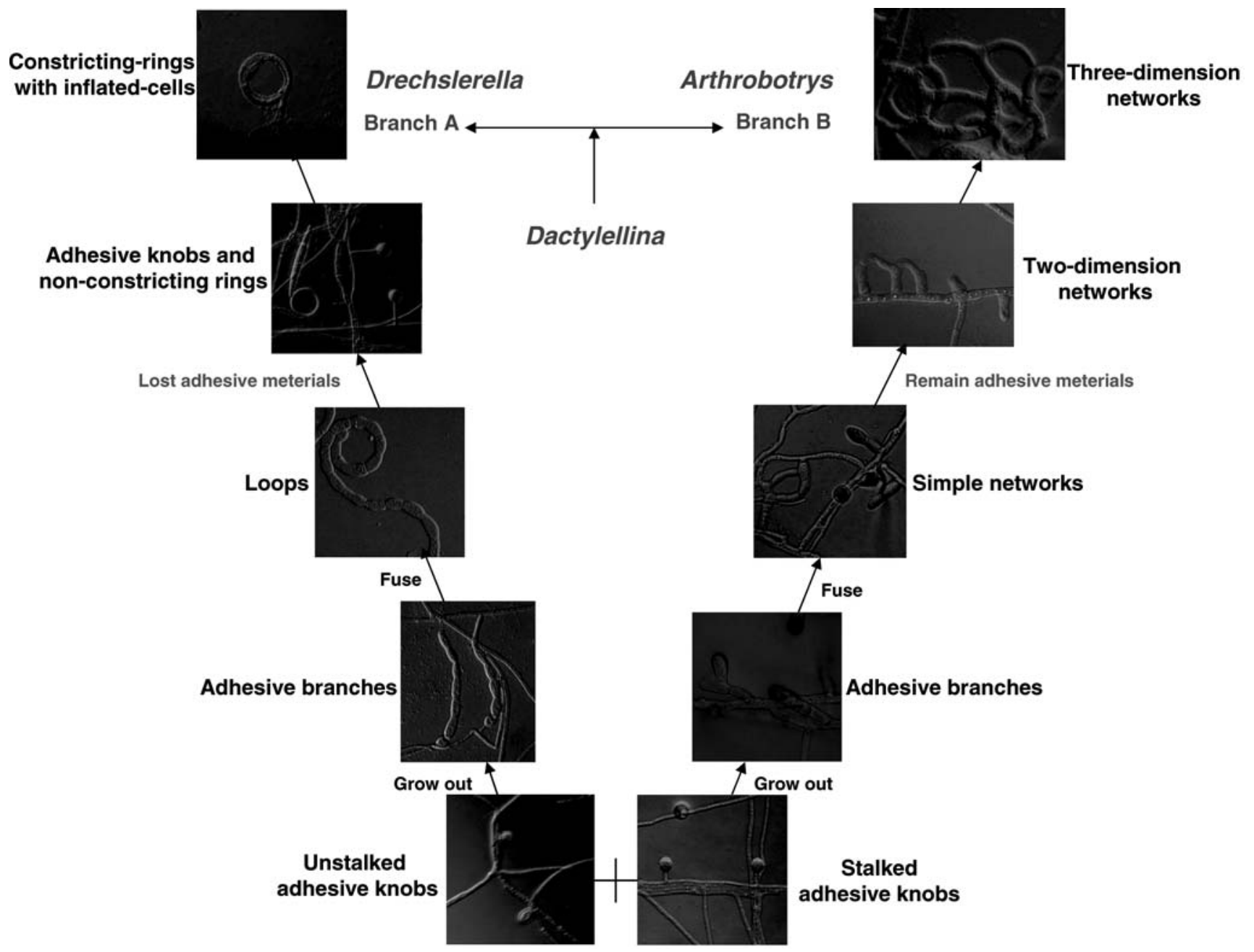

FIG. 4. Hypothetical evolution model of trapping devices in nematode-trapping fungi (Orbiliales) based on molecular data and phylogenetic analyses.

Branch B). Adhesive materials play an important part in the evolution of trapping devices. Unfortunately there is insufficient molecular evidence herein to provide an overview about a general pattern of the evolution of adhesive material. Further studies are needed.

\section{ACKNOWLEDGMENTS}

This research was supported by the 973 program (No. 2003CB415102), National Natural Science Foundation of China (No. 30230020) and National Key Foundation Program (Nos. 2002BA901A21, 2001DE10009-10). Molecular work and preparation of manuscript were carried out at The University of Hong Kong (CRCG 20041115 9091) and partially financed by Laboratory for Conservation and Utilization of Bio-resources (Yunnan, China). Yunnan University (China) is acknowledged for providing MSc scholarship to Yan Li. Laboratory for Conservation and Utilization of Bio-resources is acknowledged for supplying cultures. A.M.C. Tang is thanked for assistance and advice. Heidi Kong and Helen Leung are thanked for technical help.

\section{LITERATURE CITED}

Ahrén D, Faedo M, Rajashekar B, Tunlid A. 2004. Low genetic diversity among isolates of the nematodetrapping fungus Duddingtonia flagrans: evidence for recent worldwide dispersion from a single common ancestor. Mycol Res 108:1205-1214.

, Ursing BM, Tunlid A. 1998. Phylogeny of nematode-trapping fungi based on 18r DNA sequences. FEMS Microbiol Lett 158:179-184.

Barron GL. 1977. The nematode-destroying fungi. University of Guelph, Ontario. Lancaster, Pennsylvania: Lancaster Press. Top Mycobiol 1:1-140.

, Thorn RG. 1987. Destruction of nematodes by species of Pleurotus. Can J Bot 65:774-778.

Bunyard BA, Nicholson MS, Royse DJ. 1994. A systematic 
assessment of Morchella using RFLP analysis of the 28S rRNA gene. Mycologia 86:762-772.

Cooke RC, Dickinson CH. 1965. Nematode-trapping species of Dactylella and Monacrosporium. Trans $\mathrm{Br}$ Mycol Soc 48:621-629.

de Hoog GS, van Oorschot CAN. 1985. Taxonomy of the Dactylaria complex IV-VI. Key to the genera and checklist of epithets. In: de Hoog GS, ed. Taxonomy of the Dactylaria complex. Stud Mycol 26:97-122.

Dong JY, Zhao ZX, Cai L, Liu SQ, Zhang HR, Duan M, Zhang KQ. 2004. Nematicidal effect of freshwater fungal cultures against the pine-nematode, Bursaphelenchus xylophilus. Fung Divers 15:125-135.

Drechsler C. 1937. Some hyphomycetes that prey on free-living terricolous nematodes. Mycologia 29:447552.

- 1950. Several species of Dactylella and Dactylaria that capture free-living nematodes. Mycologia 42:1-79. - 1954. Some hyphomycetes that capture eelworms in Southern States. Mycologia 46:762-782.

- 1962. Some clampless hyphomycetes predacious on nematodes and rhizopods. Sydowia 15:9-25 (1961).

Duddington CL. 1951a. The ecology of predacious fungi. I. Preliminary survey. Trans Br Mycol Soc 34:322-331.

- 1951b. Further records of British predaceous fungi II. Trans Br Mycol Soc 34:194-209.

- 1955. Notes on the technique of handing predacious fungi. Trans Br Mycol Soc 38:97-103.

Farris JS, Kallersjo M, Kluge AG, Bult C. 1995. Testing significance of incongruence. Cladistics 10:315-319.

Felsenstein J. 1985. Confidence intervals on phylogenetics: an approach using bootstrap. Evolution 39:783-791.

Glass NL, Donaldson GC. 1995. Development of primer sets designed for use with the PCR to amplify conserved genes for filamentous Ascomycetes. Appl Environ Microbiol 61:1323-1330.

Glockling SL, Dick MW. 1994. Dactylella megalobrocha, a new species of nematophagous fungus with constricting ring. Mycol Res 98:845-853.

Hagedorn G, Scholler M. 1999. A reevaluation of predatory orbiliaceous fungi. I. Phylogenetic analysis using rDNA sequence data. Sydowia 51:27-48.

Hall TA. 1999. BioEdit: a user-friendly biological sequence alignment editor and analysis program for Windows 95/98/NT. Nucleic Acids Symp Ser 41:95-98.

Huelsenbeck JP, Bull JJ, Cunningham CW. 1996. Combining data in phylogenetic analysis. TREE 11:152-158.

— phylogenetic trees. Biometrics 17:754-755.

Jeewon R, Liew ECY, Hyde KD. 2002. Phylogenetic relationships of Pestalotiopsis and allied genera inferred from ribosomal DNA sequences a morphological characters. Mol Phylogenet Evol 25:378-392.

$\longrightarrow,-$ - 2004. Phylogenetic evaluation of species nomenclature of Pestalotiopsis in relation to host association. Fung Divers 17:39-55.

Jukes TH, Cantor CR. 1969. Evolution of protein molecules. In: Monro HN, ed. Mammalian protein metabolism. New York: Academic Press.

Kano S, Aimi R, Masumoto A, Kitamoto Y, Morinaga T.
2004. Physiology and molecular characteristics of a pine wilt nematode-trapping fungus, Monacrosporium megalosporum. Curr Microbiol 49:158-164.

Kishino H, Hasegawa M. 1989. Evaluation of the maximum likelihood model estimates of the evolutionary tree topologies from sequence data, and the branching order in Homonoidea. J Mol Evol 29:170-179.

Liou GY, Tzean SS. 1997. Phylogeny of the genus Arthrobotrys and allied nematode-trapping fungi based on rDNA sequences. Mycologia 89:876-884.

Liu XF, Zhang KQ. 2003. Dactylella shizishanna sp. nov., from Shizi Mountain, China. Fung Divers 14:103-107.

Liu XZ, Zhang KQ. 1994. Nematode-trapping species of Monacrosporium with special reference to two new species. Mycol Res 98:862-868.

McCulloch JS. 1977. New species of nematophagous fungi from Queensland. Trans Br Mycol Soc 68:173-179.

Mekhtieva NA. 1967. [On systematics of some nematophagous fungi.] Mikol Fitopatol 1:269-279.

- 1979. Khishchnye nematofagovye Griby-Gifomitsety [Predacious nematophagous hyphomycetes]. Akademiya Nauk Azerbaidzhanskoi SSR, Baku, 244 p.

Nees van Esenbeck CGD. 1817. Das System der Pilze und Schwämme. Würzburg.

Nylander JAA. 2004. MrModeltest 2.1. Program distributed by the author. Evolutionary Biology Centre, Uppsala University.

Page RDM. 1996. Treeview: an application to display phylogenetic trees on personal computers. CABIOS 12:357-358.

Pfister DH. 1997. Castor, Pollux and life histories of fungi. Mycologia 89:1-23.

Posada D, Crandall KA. 1998. Modeltest: testing the model of DNA substitution. Bioinformatics 49:817-818.

Rifai MA. 1968. The hyphomycete genus Dactylaria Sacc. Reinwardtia 7:357-374.

Rubner A. 1996. Revision of predacious hyphomycetes in the Dactylella-Monacrosporium complex. Stud Mycol 39:1-134.

Saccardo PA. 1886. Sylloge Fungorum. Vol. IV. Padova.

Schenck S, Kendrick WB, Pramer D. 1977. A new nematodetrapping hyphomycete and a reevaluation of Dactylaria and Arthrobotrys. Can J Bot 55:977-985.

Scheuer C, Webster J. 1990. Dactylella arcuata sp. nov., a nematode-trapping hyphomycete. Mycol Res 94:718-720.

Scholler M, Hagedorn G, Rubner A. 1999. A reevaluation of predatory orbiliaceous fungi. II. A new generic concept. Sydowia 51:89-113.

Subramanian CV. 1963. Dactylella, Monacrosporium and Dactylina. J Indian Bot Soc 42:291-300.

Swofford DL. 2002. PAUP*: Phylogenetic Analysis Using Parsimony (*and other methods). Version 4.0b10. Sunderland, Massachusetts: Sinauer Associates.

Templeton AR. 1983. Phylogenetic inference from restriction endonuclease cleavage sites maps with particular reference to the evolution of humans and the apes. Evolution 37:269-285.

Thompson JD, Gibson TJ, Plewniak F, Jeanmougin F, Higgins DG. 1997. The Clustal X windows interface: flexible strategies for multiple sequence alignment 
aided by quality analysis tools. Nucleic Acids Res 24:4876-4882.

Vilgalys R, Hester M. 1990. Rapid genetic identification and mapping of enzymatically amplified ribosomal DNA from several Cryptococcus species. J Bacteriol 172:42384246.

White TJ, Bruns T, Lee S, Taylor J. 1990. Amplification and direct sequencing of fungal ribosomal RNA genes for phylogenetics. In: Innis MA, Gelfand DA, Sninsky JJ,
White TJ, eds. PCR Protocols: a guide to methods and applications. San Diego, California: Academic Press. p 315-322.

Wyborn CHE, Priest D, Duddington CL. 1969. Selective technique for the determination of nematophagous fungi in soil. Soil Biol Biochem 1:101-102.

Zhang KQ, Liu XZ, Cao L. 1996. Nematophagous species of Monacrosporium from China. Mycol Res 100:274276. 